\title{
A importância dos anfíbios e suas características: aprendizagem por meio de uma sequência didática
}

\author{
The importance of amphibians and its characteristics: learning through a \\ didactic sequence
}

\section{La importancia de los anfibios y sus características: el aprendizaje a través de una secuencia didáctica}

\author{
João Lucas Lago Canhete (joaolucaslago@gmail.com) \\ Universidade Federal de Mato Grosso do Sul.
}

Fernanda Zandonadi Ramos (fernanda.zandonadi@ufms.br)

Universidade Federal de Mato Grosso do Sul.

\begin{abstract}
Resumo: Essa pesquisa, de conclusão de curso, objetivou verificar se uma sequência didática (SD), fundamentada nas ideias de Vigotski, pode propiciar contribuições para o processo de ensino e aprendizagem sobre anfíbios e sua importância ecológica. Para tal, esse trabalho foi desenvolvido com alunos de uma turma de sétimo ano de um colégio privado localizado em um município do Estado de Mato Grosso do Sul. Os dados obtidos por registros escritos, desenhos e interações discursivas gravadas em áudio, foram avaliados mediante análise de seu conteúdo. Os resultados demonstraram que a SD contribuiu para elaboração, apropriação e evolução de conhecimentos relacionados às características diagnósticas dos anfíbios, ao habitat em que eles se encontram, assim como sua importância ecológica e a necessidade da conservação desses animais.
\end{abstract}

Palavras-chave: Evolução Conceitual; Ensino e Aprendizagem; Vigotski; Classe Amphibia.

Abstract: This research, of final paper, aimed to verify if a didactic sequence (DS), substantiated on Vigotski ideas, can provide contributions to the process of teaching and learning about the amphibians and its ecologic importance. To this end, this work was developed with students of the seventh grade of a private school located in a city of Mato Grosso do Sul state. The data obtained by written records, drawings and discursive interactions recorded in audio was evaluated through content analysis. The results demonstrated that the DS contributed to the elaboration, appropriation and evolution of the knowledge rationed to the amphibian characteristics, its ecological importance and the needing of conservation of these animals.

Keywords: Conceptual Evolution; Teaching and Learning; Vigotski; Amphibia Class.

Resumen: Esa investigación, de trabajo de conclusión de curso, tuvo como objetivo verificar una secuencia didáctica (SD), basada en las ideas de Vigotski, siendo capaz de proveer contribuciones al proceso de enseñanza y aprendizaje sobre los anfibios y su importancia ecológica. Para tanto, esta pesquisa se desarrolló con alumnos de un curso de séptimo año de

Recebido em: 26/02/2021

Aceite em: 25/07/2021 
una escuela privada ubicada en un municipio del estado de Mato Grosso do Sul. Los datos obtenidos de registros escritos, dibujos e interacciones discursivas grabadas en audio fueron evaluados mediante el análisis de su contenido. Los resultados presentan que la SD contribuyó con el desarrollo, apropiación y evolución de conocimientos relacionados con las características diagnósticas de los anfibios, el hábitat en que ellos se encuentran, así como su importancia ecológica y la necesidad de conservación de esos animales.

Palabras-clave: Evolución conceptual; Enseñanza y Aprendizaje; Vygotsky; Clase Amphibia

\section{INTRODUÇÃO}

O presente estudo é resultado da monografia apresentada como trabalho de conclusão de curso em Ciências Biológicas - Licenciatura, de uma universidade pública localizada no Estado de Mato Grosso do Sul, em que, a partir de experiências vivenciadas durante o desenvolvimento do Estágio Obrigatório em Ciências Físicas e Biológicas, percebemos as dificuldades e limitações dos alunos de uma turma de sétimo ano - Ensino Fundamental, de uma escola privada localizada no mesmo Estado, com os conteúdos relacionados aos Anfíbios.

Esse estágio é realizado no sexto semestre do curso, proporcionando aos acadêmicos experiências no âmbito educacional e em sala de aula no nível de Ensino Fundamental como, por exemplo, observação da realidade escolar e de aulas do professor regente, coparticipação e regência. Nestes momentos, adquirimos conhecimentos práticos relacionados à ação docente, de forma orientada e supervisionada.

Durante a regência, observamos que os alunos tinham dificuldades em reconhecer anfíbios e/ou diferenciá-los de répteis. Além disso, não compreendiam a importância ecológica desses animais e, ainda, não tinham ideia sobre quais seriam as consequências ambientais se caso houvesse a extinção de alguns animais desse grupo como, por exemplo, os anuros.

Com relação a esse último aspecto, destacamos que os anfíbios são controladores populacionais de insetos e outros invertebrados, além disso, servem de alimento para muitas espécies de vertebrados como, por exemplo, répteis, aves, mamíferos e outros anfíbios (DUELLMAN e TRUEB, 1994).

Desse modo, consideramos que os anfíbios são animais importantes nas cadeias e teias ecológicas e sua extinção e/ou grande perda populacional pode causar um impacto significativo nas relações ecológicas existentes no meio ambiente, representando um grande

Recebido em: 26/02/2021

Aceite em: 25/07/2021 
aumento do número de insetos e, também, perda de uma fonte de alimento para outros animais.

Ademais, por ser um grupo de animais exigentes com relação ao habitat que ocupam, sendo sensíveis às transformações realizadas pelos seres humanos, alguns pesquisadores utilizam eles como indicadores da qualidade dos ambientes (SEYMOUR et al., 2001).

Considerando os aspectos citados, ressaltamos a necessidade dos conteúdos de Anfíbios serem trabalhados com os alunos do Ensino Fundamental de forma que as características morfológicas e a importância ecológica dos animais desse grupo sejam relacionadas. Ademais, também, destacamos ser essencial o direcionamento para as questões ambientais, principalmente, em relação às consequências que poderiam ocorrer caso grande número dos representantes desse grupo desaparecesse.

Apesar da necessidade de se trabalhar o conteúdo conforme explicitado, segundo Kindel, Wortmann e Souza (1997), os livros didáticos não trazem uma abordagem que relacione as características dos anfíbios com as questões ambientais e os problemas causados pela possível diminuição brusca e/ou extinção de alguma espécie, o que julgamos fundamental para o desenvolvimento de um pensamento crítico e reflexivo em que o aluno, a partir dessa relação e da apropriação desses conhecimentos, posicione-se de maneira autônoma e responsável ao perceber que ele pode ser um agente transformador do ambiente.

Ressaltamos que o compromisso com o exercício pleno da cidadania, através da capacidade de atuação no mundo e na sociedade, está descrito no documento da Base Nacional Comum Curricular (BNCC), que visa o letramento científico do estudante, para que ele possa compreender e transformar o mundo de acordo com os aportes teóricos das ciências (BRASIL, 2018, p.321)

Outro fator que pode limitar o processo de ensino-aprendizagem dos conteúdos de anfíbios está relacionado a alguns conhecimentos populares que podem ocasionar certos receios aos indivíduos. Tal fato encontra respaldo no relato de Woehl (2008), ao descrever sobre a discriminação que envolve os animais desse grupo, pois essa pode estar ligada ao fato de eles estarem cercados de mitos e lendas vindos de diversas culturas que se espalharam pelo mundo, por exemplo, podemos citar que muitas pessoas ainda acreditam que o sapo quando irritado pode expelir urina, e esta ao entrar em contato com os olhos pode cegar.

Recebido em: 26/02/2021

Aceite em: 25/07/2021 
Nesse sentido, considerando os aspectos discutidos e as limitações evidenciadas ao identificar as concepções dos alunos sobre a temática em epígrafe, desenvolvemos uma sequência didática (SD), elaborada pela adaptação da sequência de atividades proposta por Ramos (2012) - que foi utilizada como modelo.

Segundo Zabala (2010, p.18), a sequência didática é "um conjunto de atividades ordenadas, estruturadas e articuladas para a realização de certos objetivos educacionais, que têm um princípio, um meio e um fim, todos conhecidos tanto pelos professores como pelos alunos". Ademais, segundo o mesmo autor, ela é uma maneira de articular diferentes atividades ao longo de um conteúdo e, também, analisar a contribuição de cada uma delas, avaliando o seu grau de influência na construção do conhecimento do indivíduo.

Tal sequência foi fundamentada em uma perspectiva histórico-cultural do desenvolvimento humano, a partir das ideias de Vigotski (2009). Assim, objetivamos analisar se a SD adaptada para os conteúdos de anfíbios pode propiciar contribuições no processo de ensino e aprendizagem da temática em epígrafe. A seguir, apresentamos a SD utilizada neste trabalho.

\section{SEQUÊNCIA DIDÁTICA E OS PROCEDIMENTOS METODOLÓGICOS}

A sequência didática elaborada para esta pesquisa foi desenvolvida em um colégio privado localizado em Campo Grande - Mato Grosso do Sul, em uma turma do sétimo ano do Ensino Fundamental.

Para a elaboração desta utilizamos três características básicas da sequência de atividades tida como referência - proposta por Ramos (2012): 1) identificação dos conhecimentos já apropriados pelos alunos; 2) sistematização do conhecimento científico; e 3) identificação da evolução conceitual.

Na primeira etapa da SD, objetivamos identificar os conhecimentos já apropriados pelos alunos sobre a classe Amphibia. Para tal, solicitamos que eles desenhassem representantes dessa classe e, posteriormente, denominassem os animais ilustrados. Desse modo, identificamos a representação simbólica dos alunos em relação aos anfíbios.

Consideramos essencial o uso do desenho nessa etapa, pois a partir dos trabalhos de Ramos e Silva (2013, p. 81), fundamentadas nas ideias de Vigotski (2009), entendemos que o desenho pode ser "considerado como uma linguagem gráfica que tem sua origem baseada na linguagem verbal". Ademais, baseados nas mesmas autoras e de acordo com Fontana e Cruz

Recebido em: 26/02/2021

Aceite em: 25/07/2021 
(1997), também guiadas pela teoria de Vigotski, podemos destacar que os desenhos podem ser indicadores do nível cognitivo dos alunos, expressando - sem utilizar palavras - aquilo que eles já conhecem sobre o conteúdo a ser trabalhado na aula.

Após essa primeira atividade, como discutido anteriormente, devido a necessidade de trabalhar esse conteúdo com foco em aspectos e importâncias ecológicas e de conservação dos anfíbios, identificamos a concepção que os alunos apresentavam em relação a essas abordagens, a partir da seguinte situação problema:

- "Imagine que em um futuro não muito distante o crescente desmatamento da vegetação, a destruição de nascentes e também assoreamento dos rios fizeram com que muitos animais fossem extintos e, entre eles, os anfíbios. De acordo com a sua concepção quais seriam as principais consequências do desaparecimento dos anfíbios?”.

Ademais, visando saber qual a percepção dos alunos em relação à importância desses animais para a natureza e o homem, os alunos responderam a seguinte questão: "Qual a importância dos anfíbios?”.

O uso de questões e/ou, ainda, de situação-problema pode contribuir significativamente para o processo de ensino e aprendizagem, pois fornece ao professor subsídios necessários para entender os conhecimentos já apropriados pelos alunos, dando suporte para o desenvolvimento de atividades que possam articular os conhecimentos espontâneos/cotidianos com os sistematizados a serem trabalhados na aula, o que propicia a internalização de tais conhecimentos e, consequentemente, a formação e evolução conceitual.

Tal ideia encontra respaldo em Cavalcanti (2005, p. 196), ao destacar que os experimentos de Vigotski e seus colaboradores "revelaram que a formação de conceitos é um processo criativo, orientado para a solução de problemas".

Posteriormente, desenvolvemos um opinário apresentando aos alunos imagens/fotografias de animais pertencentes à classe Amphibia e também de indivíduos não pertencentes a ela. Esse, constituído pelas seguintes alternativas: a) é um anfíbio; b) não é um anfíbio; c) acho que é um anfíbio; d) acho que não é um anfíbio; e) “não sei”. Em seguida, os alunos justificaram suas respostas pela descrição das características que eles consideraram para incluir ou excluir os animais do grupo em estudo. 
Segundo Laville e Dionne (1999), o opinário é uma ferramenta capaz de captar as impressões dos pesquisados, variando de totalmente de acordo a totalmente em desacordo a partir de alternativas como, i) É, ii) Acho que é, iii) Não sei, iv) Acho que não é, e v) Não é.

É importante ressaltar que, para a teoria construtivista que fundamenta a SD, considerar os saberes já apropriados pelos alunos (conhecimento espontâneo - elaborados a partir das relações sociais) é essencial para a elaboração dos conhecimentos científicos, pois para Vigotski (2009) ensinar aquilo que o aluno já sabe fazer sozinho é tão improdutivo quanto ensinar o que está além da sua capacidade cognitiva. Além disso, segundo o teórico, é no confronto entre esses conhecimentos e os científicos (sistematizados) que há apropriação e evolução conceitual, o que justifica o desenvolvimento da próxima etapa da sequência.

Na segunda etapa da SD, a partir de aulas teóricas, expositivas e dialogadas os conceitos foram trabalhados de forma sistematizada e as respostas dadas pelos alunos foram articuladas e/ou confrontadas com os conhecimentos científicos.

Para construção do conhecimento, também, utilizamos fotografias de diferentes anfíbios e trabalhamos conteúdos que abordavam as características diagnósticas do grupo, hábitos de alimentação e de vida, aspectos e importâncias ecológicas e de conservação, assim como os mitos que estão relacionados com esses animais. Com relação a este último aspecto, durante a aula trabalhamos a seguinte tirinha.
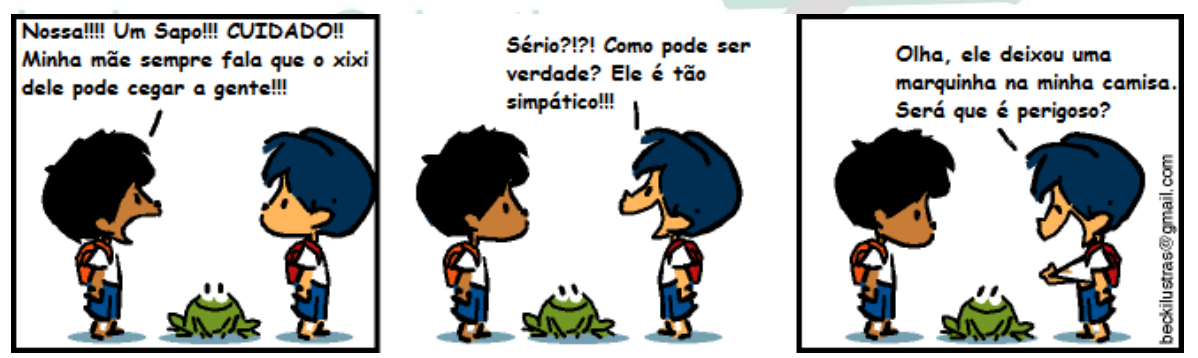

Figura 1 - Charge adaptada (Fonte original:

http://tirasarmandinho.tumblr.com/ppost/104917354199/camisetas-do-armandinho-no-link).

Vale ressaltar que esta tirinha foi adaptada pelos autores para representar a temática abordada e que a versão original pode ser encontrada no site descrito na legenda da figura 1. Ela foi utilizada para que os alunos refletissem sobre os mitos relacionados a esse grupo de animais e também para verificarmos se eles são influenciados por tais mitos.

Na terceira etapa da SD, para avaliar a evolução conceitual dos alunos, usamos um novo opinário desenvolvido de forma inversa, ou seja, disponibilizamos imagens de animais, da

Recebido em: 26/02/2021

Aceite em: 25/07/2021 
classe Amphibia e de outros vertebrados, para que os alunos colassem essas figuras em uma folha sulfite com as mesmas categorias/alternativas do opinário anterior.

Para a obtenção dos dados, as atividades de todas as etapas foram gravadas com o auxílio de um gravador digital, além desses registros tivemos as respostas dos opinários e questionários aplicados durante a primeira etapa da SD. Os dados foram avaliados qualitativamente mediante análise do seu conteúdo e são apresentados a seguir.

\section{RESULTADOS E DISCUSSÃO}

A sequência didática foi desenvolvida em uma turma de quinze alunos do sétimo ano. Porém, para essa pesquisa utilizamos os dados de apenas sete desses alunos, pois estes participaram de todas as etapas dessa sequência. A seguir, apresentamos os resultados obtidos no processo de identificação, elaboração e apropriação de conhecimentos.

$\mathrm{Na}$ primeira etapa da SD, pelos desenhos percebemos que a maioria dos alunos apresentou a concepção de que os sapos fazem parte do grupo dos anfíbios, pois apenas um aluno não representou esse animal. Porém muitos representaram também lagartixa ou lagarto, a partir disso acreditamos que esses alunos confundem os anfíbios com répteis já que os desenhos representavam também animais dessa classe como, por exemplo, jacaré, lagartixa e cobra (Fig 2A e 2B). Cabe ressaltar que apenas um aluno não representou nenhum anfíbio, desenhando apenas répteis (Fig 2C).

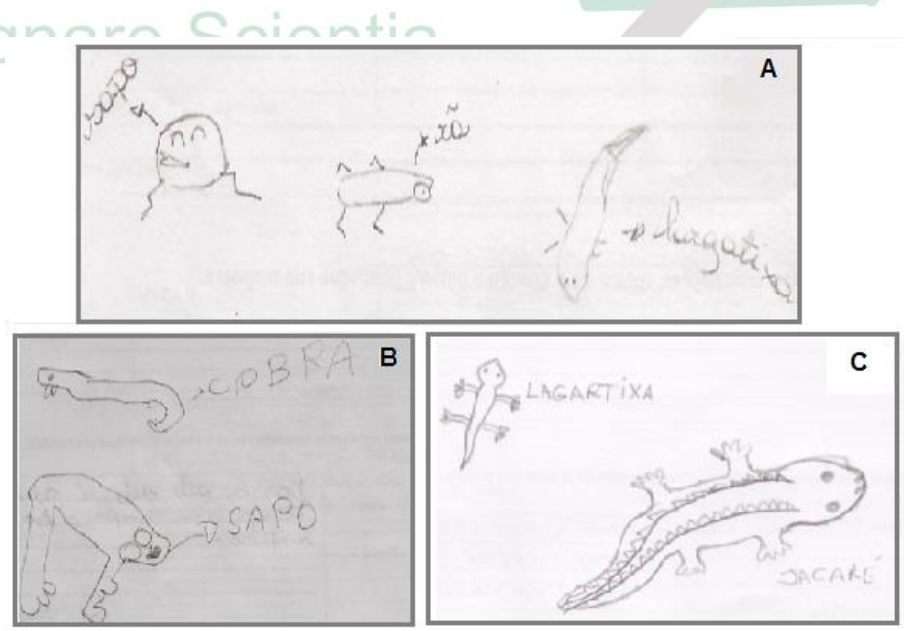

Figura 2 -Representação simbólica dos alunos sobre os animais pertencentes ao grupo dos anfíbios.

Com o desenvolvimento da primeira questão, que objetivava identificar a concepção dos estudantes em relação ao o que aconteceria se os anfíbios fossem extintos, observamos que dois alunos apresentaram ideias que fugiam do contexto ambiental ao qual a situação

Recebido em: 26/02/2021

Aceite em: 25/07/2021 
problema se firmava, pois, um aluno relacionou com "perdas sentimentais" ao descrever como consequência que "algumas pessoas ficariam tristes", e o outro apenas reforçou o enunciado da pergunta. As demais respostas foram transcritas na íntegra e agrupadas em duas categorias que representam conceitos relacionados ao equilíbrio/desequilíbrio ecológico e a cadeia alimentar, como podemos observar a seguir:

Equilíbrio/desequilíbrio ecológico: algumas respostas apresentam conceitos relacionados aos processos de desequilíbrio ocasionados pelo desaparecimento do animal predador e, consequentemente, o aumento populacional das presas, o que conforme a fala dos alunos iria causar "desordem" ou "prejuízos" relacionados à biodiversidade e/ou equilíbrio ambiental, como podemos observar nas respostas abaixo:

Aluno 1: O número de insetos ia aumentar bastante, e ia prejudicar a biodiversidade e o equilíbrio ambiental ia entrar em desordem.

Aluno 2: Muitos anfíbios são predadores, então poderia vir a faltar. A lagartixa, por exemplo, come os insetos da casa e sem ela poderia ocorrer uma invasão de insetos.

Aluno 4: Os anfíbios são animais que comem alguns insetos, como: sapo come mosca, lagartixa come escorpião, aranha, etc...

Considerando o processo de formação conceitual defendido por Vigotski (2009), destacamos que o termo biodiversidade citado na resposta do aluno 1 demonstra uma perspectiva do pensamento sincrético, em que o significado da palavra parece não estar vinculado à sua representação. O aluno estabeleceu vínculos associativos entre o aumento de insetos e o prejuízo à biodiversidade, a partir de um vínculo subjetivo. Isso ocorre pelo fato do conceito ainda não estar formado, ou seja, nesse nível a palavra expressa pelo aluno pode coincidir com a utilizada pelo professor, mas sem a apropriação do seu significado.

Nessa perspectiva, Monaco e Marandino (2010 p.16) destacam que "tratar a biodiversidade em contextos educacionais não se restringe aos seus aspectos conceituais”. Para as autoras, definir esse conceito é um enorme desafio, pois envolve aspectos não só biológicos e/ou evolutivos, mas culturais, socioeconômicos, políticos, éticos e de abordagens de espaço e tempo, conservacionista e humana. Ademais, Motokane, Kawasaki e Oliveira (2010) destacam a dificuldade em discutir a temática em epígrafe por ser um termo polissêmico.

Recebido em: 26/02/2021

Aceite em: 25/07/2021 
Apesar da importância dessa temática para o ensino de Ciências e de sua discussão para construção de significados e formação conceitual, destacamos que não houve uma discussão sistematizada sobre os conceitos de biodiversidade durante o desenvolvimento da pesquisa.

Com relação às respostas dos alunos 2 e 4, podemos observar uma visão simplista e utilitarista dos anfíbios, pois os animais desse grupo foram considerados importantes por proporcionarem um certo tipo de "equilíbrio ecológico", pois na concepção dos alunos a falta e/ou extinção deles apenas ocasionaria o aumento do número de insetos.

Ademais, corroborando com os dados apresentados na primeira atividade, ainda podemos observar no relato dos alunos 2 e 4 que eles têm a concepção de que a lagartixa faz parte dos anfíbios, pois além da representação nos desenhos eles citam esse animal como anfíbio para exemplificar suas respostas. Provavelmente, essa concepção pode estar relacionada com o hábito alimentar dos animais, visto que sapos e lagartixas se alimentam de insetos. Além disso, observamos na fala do aluno 4 que ele confunde insetos com aracnídeos, pois escreveu que anfíbios se alimentam de insetos e ao exemplificar relatou que lagartixa come escorpião e aranha.

Cadeia alimentar: nessa categoria os discursos não citaram somente o aumento populacional das presas, mas também o efeito que a extinção teria nos predadores dos anfíbios, os quais ficariam sem uma fonte de alimento, como podemos observar a seguir:

Aluno 6: Ia ter muitas moscas por causa dos sapos que as comem, os predadores dos anfíbios não iam ter o que comer e assim acabaria com o ciclo de presas e predadores.

Aluno 7: Eu acho que a presença de insetos iria aumentar, e causaria a extinção da cadeia alimentar, pois quem se alimenta dos anfíbios ia ser extinto e assim seria com o resto dos animais.

Podemos observar que esses alunos apresentaram ter conhecimento sobre cadeia alimentar, pois deixam claro que sabem quem exerce o papel de presa e predador. Podemos ver que os dois citam a mosca como a principal fonte de alimento dos sapos e argumentam que sem o predador o número desses insetos aumentaria. Outro ponto importante é que eles demonstram em suas respostas que os anfíbios também servem de alimento para outros animais e que a extinção deles causaria a perda de uma fonte de alimento para esses predadores.

Recebido em: 26/02/2021

Aceite em: 25/07/2021 
Ainda nas atividades da primeira etapa da sequência didática, os alunos responderam a seguinte pergunta: "De acordo com a sua concepção, qual a importância dos anfíbios?". Essa objetivou verificar se o aluno compreendia a importância desses animais não somente para os homens, mas também o papel deles na natureza.

Nas respostas apresentadas pelos alunos observamos que alguns compreendem que os anfíbios são importantes para o controle do número de insetos no meio ambiente como podemos evidenciar na fala de alguns alunos: "Manter o equilíbrio ambiental, a biodiversidade, e diminuir o número de alguns insetos, pois alguns anfíbios comem insetos" (Aluno 1), "Acabar com os bichinhos que nos incomodam como as moscas" (aluno 6) e "Eles comem insetos" (aluno 7).

Podemos notar em vários discursos apresentados ao longo deste trabalho que uma visão utilitarista do grupo se fez presente. Devemos ter cuidado para não limitar a importância de qualquer grupo de animais a sua utilidade dentro do ecossistema, pois, concordando com Weelie e Wals (2002, apud MONACO e MARANDINO, 2010), entendemos que o educar para biodiversidade deve ultrapassar as relações entre os seres vivos e o meio ambiente, abrangendo questões políticas, de apreciação e contemplação na dimensão estética, contribuindo para a compreensão da natureza e do próprio sujeito.

Também percebemos que eles compreendem que os anfíbios são importantes na composição da biodiversidade da fauna do nosso país, como é o caso do aluno 1 , já citado a cima e também do aluno 5, ao relatar que por "existirem muitos anfíbios, eles são muito responsáveis pela diversidade de animais no Brasil."

Novamente, pelo discurso do aluno 5, podemos observar que o conceito de diversidade, assim como biodiversidade, se encontra a nível de pensamento sincrético, baseado na perspectiva Vigotskiana relacionada a formação conceitual (VIGOTSKI, 2009), pois o aluno estabeleceu vínculos associativos a partir de uma única característica, ou seja, a quantidade de anfíbios como responsável pela diversidade de animais no Brasil.

Observamos que as respostas dos alunos ficaram restritas ao controle populacional de insetos, ou seja, eles não conhecem outros aspectos importantes do grupo como, por exemplo, indicar a qualidade do ambiente em que eles ocorrem.

$\mathrm{Na}$ terceira atividade os alunos responderam a um opinário, a partir da visualização de imagens de animais vertebrados que pertencem ou não ao grupo dos anfíbios, e classificaram

Recebido em: 26/02/2021

Aceite em: 25/07/2021 
os mesmos em uma das cinco opções presentes no opinário: é um anfíbio, não é um anfíbio, acho que é um anfíbio, acho que não é um anfíbio ou "não sei" quando eles não soubessem a qual grupo o animal pertencia.

Após marcarem a alternativa, eles foram orientados a justificar suas respostas com base nas características que o animal apresentava como, por exemplo, sua pele, membros, entre outras coisas, isso para evitarmos justificativas como "porque sim" ou "porque não".

$\mathrm{Na}$ imagem da Salamandra, 4 alunos marcaram a alternativa B, demonstrando incerteza se o animal era realmente um anfíbio. Esses alunos justificaram suas respostas de acordo com as características da pele, dizendo que "a pele é oleosa e parece um sapo, e o sapo é um anfíbio" (Aluno 3), "é diferente e tem quatro patinhas e é um animal liso como um sapo" (Aluno 5) e "porque a pele se parece com a de um sapo". Apenas um aluno marcou a alternativa correta, relatando que "a pele dele é bem lisa igual a dos anfíbios", o que demonstra apontar uma característica comum a todos os anfíbios.

Ao visualizarem uma perereca, seis alunos marcaram a alternativa correta e, também, justificaram suas respostas pela característica da pele e aparência com sapos. Desse modo, compreendemos que eles apresentam a concepção de que o sapo pertence ao grupo dos anfíbios, mesmo a imagem mostrando uma perereca. Além disso, o aluno 3 apontou a peculiaridade da pele oleosa como característica diagnóstica desse grupo.

Na imagem da Gymnophiona, seis alunos marcaram que o animal não era um anfíbio (E), justificando suas respostas dizendo que "deve ser uma minhoca ou um piolho de cobra, e eles são de outra classe" (aluno 4), "Pois é uma minhoca e ela pertence a outro grupo" (Aluno 3) e "não possui praticamente nenhuma característica de anfíbios" (Aluno 2).

Vemos nessas respostas que os alunos 4 e 3 confundem esse animal com a minhoca, pois esse animal foge do padrão dos anfíbios e dos demais vertebrados, como justificado pelo aluno 2, pois ele não possui nenhum membro e possui um corpo esguio como o da minhoca corroborando com a justificativa do aluno 6, que assinalou a alternativa D e descreveu: "acho que não se encaixa nas características de um anfíbio".

$\mathrm{Na}$ foto da Gekotta não houve consenso entre as respostas, visto que apenas um marcou a alternativa correta (E) e justificou dizendo que "a pele é áspera" (aluno 1), sendo assim para esse aluno o fato desse animal apresentar a pele áspera, devido à presença de escamas, não é uma característica dos anfíbios. Os alunos que assinalaram a alternativa "Eu acho que é um

Recebido em: 26/02/2021

Aceite em: 25/07/2021 
anfíbio" (B) justificaram suas respostas dizendo que o animal "Parece ser um lagarto (...)" (Aluno 4) e/ou que “possuía as mesmas características que o animal da figura 2" (Aluno 7). Desse modo, podemos ver que além dos alunos confundirem o animal da imagem com a perereca, ainda apresentam a concepção que os lagartos são anfíbios, o que reforça a concepção demonstrada na atividade da primeira etapa da SD.

Ao visualizarem o lagarto, quatro alunos marcaram a opção B defendendo sua opinião pelos seguintes argumentos: "parece ser uma lagartixa com cauda grande" (aluno 4); "ele parece com uma cobra” (aluno 3). Nesse caso, consideramos que os alunos confundem os répteis com os anfíbios. Tal ideia é reforçada quando os alunos analisam a figura da lagartixa, já que quatro alunos marcaram a alternativa $\mathrm{B}$ e outros dois assinalaram a alternativa $\mathrm{A}$, justificando suas respostas pelo fato dela grudar e escalar.

Já na imagem da Amphisbaena três alunos apresentaram a concepção correta de que esse animal não pertence aos anfíbios, entretanto suas justificativas não apresentaram nenhuma contribuição dizendo apenas que "não tem características de anfíbio" (aluno 2), "porque geralmente anfibios tem perna" e "pois não tem patinhas e não gruda" (aluno 5).

Na cobra, três alunos marcaram a opção C, "Não sei", entretanto, as justificativas apresentadas pelos alunos não traziam nenhum elemento que pudesse ser discutido ou que justificasse a escolha dessa alternativa. Nessa imagem houve apenas um aluno que apresentou a concepção correta, marcando a alternativa $E$, não é um anfíbio, sendo que a justificativa usada por ele foi que "a imagem é uma cobra" (aluno 5).

$\mathrm{Na}$ imagem de um peixe três alunos marcaram a alternativa "Não sei", um deles relatou que não sabia se os animais aquáticos faziam parte do grupo, desse modo podemos ver que esse aluno não apresenta uma concepção sobre o hábito de vida dos anfíbios. Apenas dois alunos apresentaram a concepção correta e um aluno justificou afirmando que "a imagem é um peixe". Um aluno marcou a opção A, "É um anfíbio", e justificou dizendo que "Eu acho que é um girino" (Aluno 4), com base nessa resposta podemos notar que o aluno conhece os estágios de desenvolvimento dos anuros, entretanto ele associa o girino com um peixe, talvez porque ele já tenha visto algum, por causa do ambiente em que o animal da foto estava ou por causa da falta de escala da imagem.

Quando visualizaram a foto de um sapo, seis alunos apresentaram a concepção correta assinalando a alternativa A, justificando suas respostas seguindo a mesma linha de raciocínio:

Recebido em: 26/02/2021

Aceite em: 25/07/2021 
“É um sapo e sapo é um anfibio”. Desse modo, podemos perceber que sapo eles reconhecem como anfíbio.

$\mathrm{Na}$ imagem do cágado e da pirambóia, a maioria dos alunos marcaram a opção C, "Não sei” e não souberam justificar.

De modo geral, nas respostas do opinário podemos observar que os alunos tiveram dificuldades em identificar os animais que pertencem aos anfíbios, a Gymnophiona foi o animal que eles mais tiveram dúvidas se pertencia ou não a esse grupo e o sapo o animal que mais associaram como representante do mesmo, a partir disso eles buscavam comparar as características dos outros animais com a do sapo como, por exemplo, a pele oleosa, a presença de patas, entre outras.

Com base nessa concepção, Fontana (1993, p.125) descreve "que frente a um conceito sistematizado desconhecido a criança busca significá-lo por meio da aproximação com outros já conhecidos/internalizados, objetivando enraizá-los mediante a uma experiência concreta", o que explicaria o fato de, em alguns casos, os alunos compararem os animais com o sapo.

Ademais, podemos observar que a atividade com o uso do opinário propiciou contribuições significativa para o início do processo de formação conceitual em nível de pensamento por complexo, pois os alunos usaram as representações simbólicas/imagens para agrupar características semelhantes ao que eles reconheciam como as pertencentes aos anfíbios.

Segundo Vigotski (2009), nesse estágio do processo de formação conceitual, o sujeito se encontra em um plano do pensamento concreto-factual e este se apresenta coerente e objetivo. Nesse caso, o sujeito passa a estabelecer relações entre as diferentes impressões, a unificar características semelhantes a um grupo comum, agrupando-os e generalizando-os a um complexo estabelecido, agora, a partir de vínculos objetivos existentes entre as características observadas nas imagens. Ressaltamos que a coerência e objetividade desenvolvida neste estágio ainda não são equivalentes ao pensamento conceitual.

Após análise dos resultados obtidos, iniciamos a aula teórica de forma dialogada. Ressaltamos que na aula consideramos e retomamos tais resultados, pois segundo Oliveira (1997, p.62), baseada nas obras de Vigotski, o processo de ensino-aprendizagem dentro da escola deve ser construído e tomando como ponto de partida o desenvolvimento real da criança.

Recebido em: 26/02/2021

Aceite em: 25/07/2021 
No início da aula, questionamos os alunos se os anfíbios poderiam causar algum mal para nós, com isso percebemos que alguns demonstraram dúvidas quanto à nocividade dos anfíbios, relatando: "eu acho que a grande maioria os anfíbios são inofensivos"; "acho que não, porque os anfíbios são animais pequenos". Outros mostraram algum tipo de receio em seus discursos, reconhecendo que esses animais possuem algum tipo de veneno, como apresentado abaixo:

Aluno 1: Sim, pois alguns são venenosos, alguns podem causar doenças e outros se não for levado ao médico podem matar;

Aluno 3: Sim, alguns anfíbios podem nos deixar cegos, outros podem injetar veneno em nosso sangue;

Aluno 4: Sim, pois alguns deles podem matar;

Aluno 5: Muitos deles causam doenças muito sérias.

Aluno 2: Dependendo da espécie, pode causar sim algum mal, pois algumas espécies de anfíbios possuem veneno, e é para ser usado contra predador.

Podemos observar nas respostas desses alunos que eles estabelecem relação com prejuízos ocasionados com a saúde humana, variando desde doenças até a morte. No relato do aluno 3 podemos notar a presença de duas concepções equivocadas, a de que o veneno dos sapos pode nos deixar cego e também que eles injetam veneno em nosso corpo, provavelmente, ele fez referência ao mito que a urina do sapo pode nos cegar, além de acreditar que de algum modo o animal pode injetar veneno em nosso corpo.

Destacamos também a resposta do aluno 2 que demonstrou a compreensão de que o veneno do corpo dos anfíbios é um tipo de defesa usado contra predadores, entretanto ele não foge da concepção que esses animais podem nos causar algum mal, afirmando que “dependendo da espécie, pode causar algum mau sim (...)”.

Posteriormente, trabalhamos a charge (figura 1) e alguns alunos relataram que: "tem um negócio que eu acho que fica perto da cabeça que sai veneno quando você aperta o sapo", nesse discurso o aluno demonstra o conhecimento do local em que o veneno é encontrado (glândula paratóide), e que tal substância só é expelida quando o animal é apertado. Outro aluno relatou o seguinte: "vi uma reportagem que falava que para se defender ele solta um tipo de veneno". Houve também aqueles que apresentaram um conhecimento adquirido no

Recebido em: 26/02/2021

Aceite em: 25/07/2021 
cotidiano, relatando: "minha mãe já falou que o xixi deles é muito venenoso e é uma das coisas que mais mata". Podemos inferir que esse tipo de discurso pode ter influenciado negativamente o conceito que esse aluno tem desses animais (sapos).

Podemos perceber nos discursos supracitados algumas crendices e, também, preconceitos relacionados a esses animais. Relatos similares foram observados por Guimarães, Ribeiro e Pereira (2020), em sua pesquisa perceberam que os alunos não tinham contato afetivo com o grupo, além de que seus saberes se baseavam muito naquilo que eles “ouviram falar" de outras pessoas.

Tais resultados, também, corroboram com os evidenciados por Kindell, Wortmann e Souza (1997). Além disso, os autores relatam que pelo "preconceito" por animais desse grupo, muitas pessoas apresentam atitudes e/ou posturas que prejudicam os mesmos, por exemplo, jogando sal em sapos.

Prosseguindo com a aula, apresentamos a figura de um cladograma para que os alunos tivessem uma ideia evolutiva do grupo dos vertebrados. Assim, retomamos conceitos relacionados ao grupo anterior, discutindo com os alunos as estruturas evolutivas que permitiram aos anfíbios se beneficiar do ambiente terrestre e, posteriormente, fotografias de anfíbios, discutindo as características morfológicas de cada grupo.

Considerando que ao visualizarem a imagem do grupo das Gymnophiona (Cecília) os alunos não reconheceram o animal como um anfíbio, justificando suas respostas pela ausência de membros e corpo segmentado, na aula apresentamos um enfoque especial nas características desse grupo, comparando com a imagem da "cobras de duas cabeças" do grupo Amphisbaena (Réptil), para que os mesmos percebessem que no grupo de anfíbios há animais que possuem características diferentes do que eles estabeleceram como comum e/ou padrão ao grupo.

Um trabalho desenvolvido por Luchese (2013) afirma que é comum os estudantes confundirem os anfíbios com os répteis, por causa da semelhança entre alguns dos seus representantes.

Posteriormente, trabalhamos a importância desses animais para nós e para a natureza, assim como as possíveis consequências caso houvesse sua extinção, discutimos sobre a importância dos anfíbios como bioindicadores da qualidade dos ambientes, o desenvolvimento de fármacos baseados nas substâncias de sua pele, a atuação deles como

Recebido em: 26/02/2021

Aceite em: 25/07/2021 
fonte de alimentos para outros animais e também a preservação de algumas espécies endêmicas.

Percebemos que pela sistematização do conteúdo, a partir das discussões e atividades desenvolvidas em sala de aula, os alunos começaram a se apropriar dos conhecimentos, relacionando os conceitos mediados com os saberes já apropriados, demonstrando um processo inicial de evolução conceitual. Ademais, observamos que o uso de imagens propiciou contribuições significativas para a construção dos conhecimentos e de representações simbólicas/signo, que garantiram apropriação, formação e/ou reelaboração de conhecimentos. Ressaltamos que tais imagens proporcionaram um ensino contextualizado.

Vale destacar que para Vigotski (2009, p. 165), o sujeito orienta suas operações intelectuais utilizando o signo e, "dependendo do meio e do emprego da palavra e da sua explicação funcional, transcorre todo o processo de formação do conceito”.

Após o término da sistematização do conteúdo, desenvolvemos a última etapa da SD para identificar a apropriação e/ou evolução conceitual dos alunos.

Na primeira atividade os alunos, em dupla e/ou trio, responderam uma questão sobre a importância dos anfíbios para a nossa vida e para a natureza, assim como as principais consequências da extinção desses animais, apresentando as seguintes respostas:

Alunos 6 e 1: Controle da população de insetos, ajudam na medicina, com eles conseguimos saber se aquele ambiente estál limpo, porque se o ambiente estiver sujo ele morre

Alunos 2 e 4: Eles são animais que comem insetos, eles são alimentos para outros animais, ajudam a manter o ambiente vivo, o seu veneno pode ser usado na medicina

Alunos 3; 5 e 7: Graças a alguns anfíbios os cientistas criaram remédio para a Leishmaniose, graças a outros anfíbios temos controle de insetos se não existisse esses anfíbios iam ter muitos insetos e perderíamos a lavoura, e também da pra descobrir se o local está contaminado, pois como os anfíbios tem a pele fina por causa da respiração, as bactérias entram facilmente no sapo e matam o sapo e se alimentam.

Comparando com as respostas da primeira etapa vemos que os alunos apresentam novos conceitos relacionados à importância ecológica dos anfíbios. Antes citaram apenas que os anfíbios se alimentavam dos insetos, agora eles apresentam o conhecimento de que esses

Recebido em: 26/02/2021

Aceite em: 25/07/2021 
animais são importantes, também, para o desenvolvimento de fármacos, manutenção da dinâmica do ambiente e a atuação desses animais como bioindicadores.

Com isso, percebemos o processo de formação conceitual pela apropriação e internalização de conhecimentos, conforme o desenvolvimento das atividades da SD e mediação pedagógica. Concordando com Lorenço e Wirzbicki (2021, p.125), destacamos que "os meios pelos quais aprendemos e nos desenvolvemos tem relação com as interações sociais, com a mediação simbólica, instrumental e com as estratégias de ensino que são propostas pelo professor".

Já na segunda pergunta, os alunos responderam quais seriam as principais consequências da extinção dos anfíbios, obtivemos as seguintes respostas:

Alunos 6 e 1: Os seus predadores não iam ter alimento, aumentaria a quantidade de insetos.

Alunos 2 e 4: Vai ter uma grande concentração de insetos, sem eles pode faltar remédios que são feitos com o seu veneno

Alunos 3; 5 e7: Os fazendeiros perderiam as fazendas, lavouras e plantações, elas ficariam infestadas de insetos.

Comparando com as respostas da atividade da etapa I, percebemos que alguns conceitos foram acrescentados no discurso dos alunos, como a perda de "remédios que são feitos com o seu veneno" (alunos 2 e 4) e, também, os danos causados pelo aumento da população de insetos citado pelos alunos 3,5 e 7 .

$\mathrm{Na}$ última atividade os alunos repetiram o opinário de forma inversa, colando imagens de anfíbios e não anfíbios em uma folha A4, utilizando também algumas imagens diferentes. Abaixo apresentamos exemplos das atividades realizadas pelos alunos (Fig. 3 A, B, C e D). Nas imagens A e C as opções são "Anfíbios", "Não Anfíbios" e "Não Sei”, respectivamente, e nas imagens B e D as opções são "Acho que é um anfíbio" e "Acho que não é um anfíbio".

Recebido em: 26/02/2021

Aceite em: 25/07/2021 


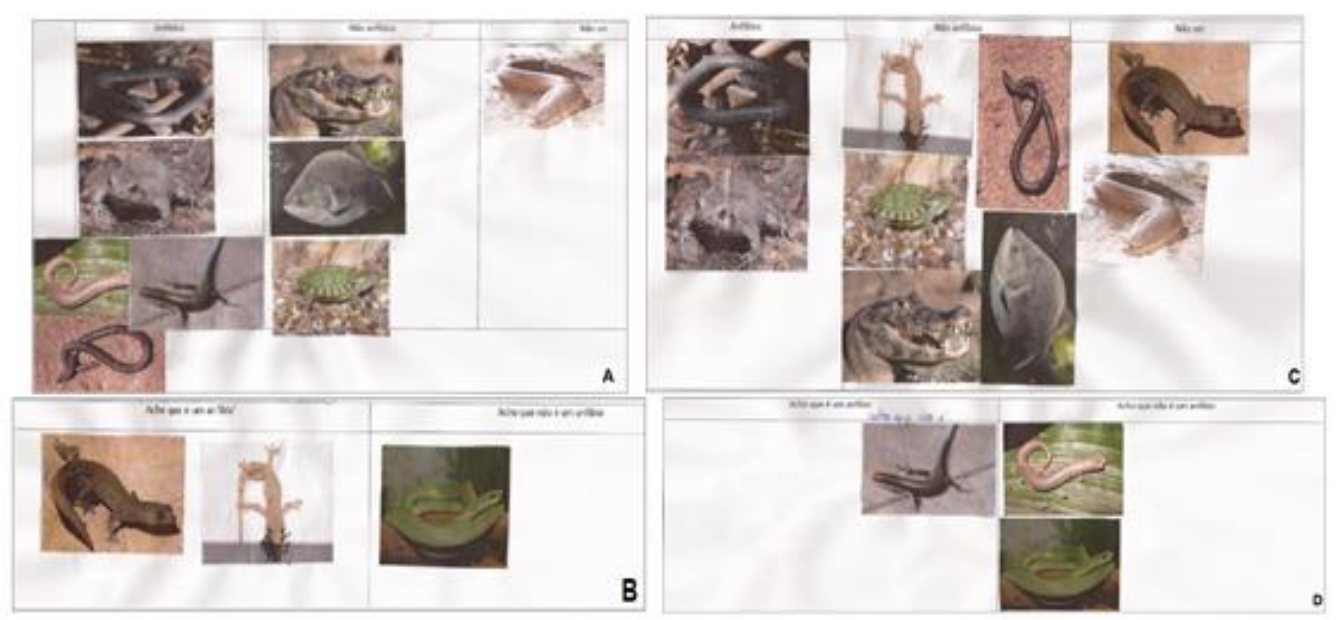

Figura 3 - Atividade de evolução conceitual dos alunos 4 e 2 (fig. A e B) e alunos 6 e 1 (Fig. C e D)

Observamos que os alunos ainda tiveram dificuldades em identificar quais animais pertenciam ao grupo dos anfíbios. Entre as imagens de animais que pertenciam a outras classes e foram agrupadas como anfíbios destacamos a Amphisbaena (1x) e o lagarto (2x). Outro ponto que observamos é que as imagens da salamandra e da cecília ainda confundiram os alunos, pois em cada imagem um grupo ficou em dúvida se eram ou não anfíbios.

Provavelmente, isso aconteceu porque dispomos de pouco tempo na sistematização do conteúdo para tratar das características morfológicas desses animais. Porém, considerando tais dificuldades, fizemos uma revisão do conteúdo e as imagens trabalhadas foram discutidas coletivamente, reforçando as características diagnósticas que identificavam o grupo.

\section{CONSIDERAÇÕES FINAIS}

Com base nos resultados obtidos podemos considerar que a sequência didática elaborada e desenvolvida nessa pesquisa, com a fundamentação teórico-metodológica Vigotskiana que a sustenta, propiciou aos alunos a elaboração e apropriação de conhecimentos relacionados às características dos anfíbios, suas importâncias ecológicas e a necessidade da conservação desses animais. Nesse sentido, destacamos que ela contribuiu para o processo de ensino e aprendizagem dos alunos, visto que eles apresentaram em seus discursos uma evolução conceitual.

Ademais, ressaltamos que o uso das fotografias possibilitou contribuições significativas para a visualização e identificação das características diagnósticas desses animais, assim como do habitat em que eles se encontram. Desse modo, contribuiu para que a representação inicialmente simbólica se transformasse em signos, ao passo que os alunos construíram significados e internalizaram conhecimentos.

Recebido em: 26/02/202 1

Aceite em: 25/07/2021 
Considerando as contribuições que essa SD propiciou no processo de ensino e aprendizagem dos conteúdos de anfíbios e sua ecologia, reforçamos a ideia de que a sequência didática utilizada como base para elaboração das atividades aqui desenvolvidas, realmente serviu como ferramenta que propiciou contribuições significativas para outros conteúdos e contexto de ensino, isso pelo processo de adaptação das atividades.

Assim, destacamos que a nossa SD também pode ser readaptada com relação à carga horária, atividades e/ou, ainda, para outros conteúdos e contextos nos quais os alunos estejam inseridos, pois a mesma não pode ser vista como uma receita a ser seguida, mas como um referencial e/ou modelo teórico-metodológico direcionado para construção de conhecimentos e evolução conceitual.

\section{REFERÊNCIAS}

BRASIL. Ministério da Educação. Base Nacional Comum Curricular. Brasília, 2018.

CAVALCANTI, L. S. Cotidiano, mediação pedagógica e formação de conceitos: uma contribuição de Vygotsky ao ensino de Geografia. Caderno CEDES, Campinas, v. 25, n. 66, p. 185-207, mai./ago. 2005.

DUELLMAN, W. E.; TRUEB, L. Biology of amphibians. JHU press, 1994.

FONTANA, R. A. C. A Elaboração conceitual: a dinâmica das interações na sala de aula. In: SMOLKA A. L. B.; GÓES, M. C. de (orgs.) A linguagem e o outro no espaço escolar: Vygotsky e a construção do conhecimento. Campinas, Papirus, 1993

FONTANA, R.; CRUZ, N. Psicologia e trabalho pedagógico. 1. ed. São Paulo: Atual, 1997. GUIMARÃES, L.; PEREIRA, J.; FERRAZ, C. Anfíbios nos anos iniciais: estratégia didática envolvendo contos de fadas para o ensino de biologia básica. Revista Insignare ScientiaRIS, v. 3, n. 5, p. 362-371, 2020.

KINDEL, E. A. I.; WORTMANN, M. L. C.; SOUZA, N. G. S. O estudo dos vertebrados na escola fundamental. São Leopoldo: Unisinos, 1997. 130 p.

LAVILLE, C.; DIONNE, J. A construção do saber: manual de metodologia da pesquisa em ciências humanas. Belo Horizonte: Editora UFMG, 1999. 262 p.

LOURENÇO, D. S; WIRZBICKI, S. M. Contribuição da teoria histórico - cultural: um olhar para as interações em sala de aula a partir dos anais do ENEBIO. Revista Insignare Scientia-RIS, v. 4, n. 3, p. 101-128, 2021.

LUCHESE, M. S. A herpetologia no ensino fundamental: o que os alunos pensam e aprendem. 27f. Monografia (Curso de Licenciatura Ciências Biológicas) - Universidade Federal do Rio Grande do Sul, Porto Alegre, 2013.

Recebido em: 26/02/2021

Aceite em: 25/07/2021 
MONACO, L. MARANDINO, M. Biodiversidade nos museus: discussões sobre a (in)existência de um discurso relativo à conservação em ações educativas dos museus de ciências. In: MARANDINO, M., MONACO, L., OLIVEIRA, A. D. Olhares sobre os diferentes contextos da biodiversidade: pesquisa, divulgação e educação.

GEENF/FEUSP/INCTTOX. São Paulo, 2010. P. 13 - 29.

MOTOKANE, M. KAWASAKI, C. S. e OLIVEIRA, L. Por que a biodiversidade pode ser um tema para o ensino de ciências? In: MARANDINO, M., MONACO, L., OLIVEIRA, A. D. Olhares sobre os diferentes contextos da biodiversidade: pesquisa, divulgação e educação. GEENF/FEUSP/INCTTOX. São Paulo, 2010. P. 30-59.

OLIVEIRA, M. K. Vygotsky Aprendizado e Desenvolvimento: Um processo sóciohistórico. São Paulo: Scipione, 1997.

RAMOS, F. Z; Limitações e contribuições da mediação de conceitos de botânica no contexto escolar. 2012. p.145. Dissertação - Mestrado em Ensino de Ciências - Fundação Universidade Federal de Mato Grosso do Sul, Campo Grande, 2012.

RAMOS, F. Z; SILVA, L. H. A. Contextualizando o Processo de Ensino-Aprendizagem de Botânica. Curitiba: Prismas, 2013.

SEYMOUR, C. L.; DE KLERK, H. M.; CHANNING, A.; CROWE T. M. The biogeography of the Anura of sub-equatorial Africa and the prioritization of areas for their conservation. Biodiversity and Conservation, n. 10, p. 2045-2076, 2001.

VIGOTSKI, L. S. Pensamento e Linguagem. São Paulo: Martins fontes, 2000

VIGOTSKI, L. S. A Construção do Pensamento e da Linguagem. 2. ed. São Paulo: WMF Martins Fontes, 2009.

WOEHL JR, G. \& WOEHL, E. N.. Anfíbios da Mata Atlântica. Jaraguá do Sul: Instituto Rã-bugio para Conservação da Biodiversidade. 61p, 2008.

ZABALA, A. A prática educativa. Porto Alegra: Artmed, 2010.

Recebido em: 26/02/2021

Aceite em: 25/07/2021 